\title{
Economic 0ptimization of the Fertilization System on Corn Crops on a Representative Soil in the Transylvanian Plain
}

\author{
Andra PORUȚIU ${ }^{*}$, Felix ARION ${ }^{2}$, Iulia MUREŞAN ${ }^{3}$, Raluca FĂRCAȘ ${ }^{4}$, Tudor SĂLĂGEAN ${ }^{5}$, Lavinia \\ MOLDOVAN $^{6}$ \\ 1,2,3 Department of Economic Sciences, University of Agricultural Sciences and Veterinary Medicine, Cluj- \\ Napoca, Romania \\ ${ }^{4}$ Department of Land and Cadastral Measurements, Technical University, Cluj-Napoca, Romania \\ ${ }^{5}$ Department of Land Measurement and Exact Science, University of Agricultural Sciences and \\ Veterinary Medicine, Cluj-Napoca, Romania \\ ${ }^{6}$ Department of Agrochemistry, University of Agricultural Sciences and Veterinary Medicine, Cluj- \\ Napoca, Romania \\ *)Corresponding author, e-mail: andra.porutiu@gmail.com
}

BulletinUASVM Horticulture 73(1) / 2016

Print ISSN 1843-5254, Electronic ISSN 1843-5394

DOI:10.15835/buasvmen-hort:11601

\begin{abstract}
The promotion during the last decades of the concept of sustainable agriculture attracted the application of principles that lead to agriculture technologies which are both technically and economically productive, providing effective solutions for protecting the environment and the consumers. They also insure the productivity of the factors involved and also an optimization of the production components. The goal of this research is to scientifically and economically substantiate the differentiated fertilization systems involved in obtaining high productions in the reference area. In this study it was track the effect of the nitrogen-phosphorous interaction in achieving the corn productions obtained in 2011. The research presents the stated results as annual (partial) values and as being reference values for further experimental years and obviously with approaches that will economically substantiate the suggested solutions. The current research is based on the production results obtained on corn crops (Turda STAR Variety) in long term experiments conducted on an argyle chernozem soil in Turda (Cluj County). The production data are obtained from these experiments, which hold objectives that target both the effect and economic efficiency of differentiated fertilizations on corn productions and also the impact of fertilizers on the soil fertility evolution, on the quality of the productions obtained. The field experience which underpins the achievement of objectives is a bi-factorial structure that tracks the effect of the NP interaction on corn. The rate of return, as a mean of all the values that derive from all nitrogen-phosphorous combinations was at a very high level, $80 \%$, with a maximum of the individual values reached at the fertilizing combination N200P160, at which the value of the production increase due to the applied dose, reached the maximum value $(6041 \mathrm{~kg} / \mathrm{ha})$. The revenue obtained from the production increase for 1 leu spent was of 2,02 lei. In case of corn crops, especially Turda STAR hybrid and an intensive fertilization, it can be currently obtained $12-14 \mathrm{t}$ grains of corn per hectare. Corn is not as sensitive as wheat, for example, to an imbalanced NP ratio and responds to this through high productions even for $\mathrm{N}$ overdoses, that can sustain high and economic corn grain productions per surface unit.
\end{abstract}

Keywords: corn crops, economic optimization, fertilization systems, nitrogen-phosphorous interaction, productions. 


\section{INTRODUCTION}

Agricultural performance as a requirement of contemporary society requires assimilation into production of all elements of technical progressscientific and economic- advanced in all its sides that determine quantitative and qualitative productivity, higher yields, economic efficiency obtained under optimum systems involved in their implementation, food safety and consumer protection.

In this study was tracked the effect of the nitrogen-phosphorous interaction in achieving corn productions. The research presents the stated results as annual (partial) values and it will continue with them as being reference values for further experimental years (as stages in long term experiments) and with approaches that will economically substantiate the suggested solutions. The production data are obtained from such experiments, framed in the "long term experiments system" from ASAS-ICDCPT Fundulea network, which hold objectives that target both the effect and efficiency of differentiated fertilizations on productions and also the impact of fertilizers on the soil fertility evolution, on the quality of the productions obtained (Poruţiu et al., 2013).

Optimizing agrochemical soil-plant system represents meeting the essential objective in a higher degree and the crops requirements to soil reaction and representation of elements and nutrients in specific concentrations and ratios between them (Borlan and Hera, 1984).

Economic approaches dedicated to ensure real management of fertilizing resources on agricultural crops (in this case, corn) are considering going through stages of scientific evidence on the economic efficiency of fertilizer application and then developing a substantiation framework for the optimization of fertilization. Obviously, these approaches involve first of all defining the concepts and objectives of establishing relevant indicators expressing fertilization efficiency and optimization in order to disseminate the results obtained in the delimitation of differentiated fertilization systems (Otiman, 1979; Otiman, 1987; Otiman and Creț, 2002, Toader et al., 2013).

Researches carried out in order to rationalize the use of fertilizers in agriculture were considered mainly in two essential directions of approach, the study of technical efficiency for determining the influence of fertilizers on the quantity and quality of vegetal production in order to optimize the soil plant system in terms of maximizing the fertilizing inputs and the research on economic efficiency and optimization of applying fertilizers in order to maximize the net revenue obtained from the differential application of fertilizing inputs.

\section{MATERIALS AND METHODS}

Experimental approaches were performed under SCDA Turda conditions, using the experimental protocol of long term experiences, first located in the agricultural year 1966/1967, for wheat-corn-soy rotation (Haș, 2006).

Corn hybrid Turda STAR has the following biological, agricultural and productive attributes: tri-linear, semi-early hybrid, with high plants and 13-15 semi erect leaves. Cob has a conical shape, medium length, with 16 rows of beans and it is red. Semi-hyaloid grain is yellow, one thousand grain weight (MMB) of $380 \mathrm{~g}$, yield $79 \%$. The grain has a chemical composition represented by 11,5 - $12,5 \%$ protein, $3,8-4,6 \%$ fat and $69,5-71,5 \%$ starch.

The field experience which underpins the achievement of objectives is a bi-factorial structure that tracks the effect of the NP interaction on corn: A factor - phosphorus doses ( $\left.k g \mathrm{P}_{2} \mathrm{O}_{5} / \mathrm{ha}\right)$ : $0 ; 40$; $80 ; 120 ; 160$ and B factor - nitrogen doses (kg N/ ha): $0 ; 50 ; 100 ; 150 ; 200$, with annual application to corn;

Soil from the nutrient experiences: according to soil mapping, pedological and agrochemical study and from the soil quality monitoring results, this soil fits the argic chernozem type, in the pedological class of cernisoils (Borlan et al., 1994).

Fertilizer used in the experiments: complex fertilizer $20-20$ is a solid, granulated nitrophosphate, which holds when applied, the effect of the interaction of the two elements from its composition $(\mathrm{N} \cdot \mathrm{P})$, here in balanced concentrations and reports (1:1) (Hera, 2008).

When harvesting the corn, production results were collected and for these the absolute increases due to phosphorus application as a fertilizer were calculated. The processing and interpretation of the data was conducted using the production curves according to polynomial models and they were graphically represented in this study.

The economic indicators tracked and studied were: 
a. Economic efficiency indicators

- Production increase per surface unit (ha) $(\Delta Q) ;$

- Value of the production increase per surface unit (ha) $\left(\mathrm{V}_{\mathrm{S}}\right)$;

- Production increase to $1 \mathrm{~kg}$ of active substance (SA) applied $(\Delta \mathrm{Q} / 1 \mathrm{~kg} \mathrm{SA})$;

- Additional costs per surface unit (ha) (Cs);

- The value of the production increase per 1 leu of additional costs $\left(\mathrm{V}_{\mathrm{s}} / 1\right.$ leu $\left.\mathrm{Cs}\right)$;

- Net revenue of the production increase following the fertilization of 1 hectare of crop (VNS);

- Unitary cost of the production increase (CUS);

- Rate of return of the production increase (Rs).

b. Economic optimization indicators

For a pertinent technical-economic analysis is necessary to achieve the following functions: technical (physical) bi-factorial function; value bifactorial function;

\section{RESULTS AND DISCUSSION}

Corn crops have a much differentiated response to the effect of applying fertilizers than wheat. First, only the results in 2011 confirm regularities in the influence of NP factor on the grain production or significant influences of the $\mathrm{N}$ and $\mathrm{P}$ factors (Fig. 1).

Actually, corn grain production (Turda STAR hybrid) is very variable from year to year, the quantitative results in 2012 and 2013 are less than half of the productions obtained in 2011. Climate disorders slashed the production of those years.

The synthesis of the production results obtained for corn linked to the NP fertilization proves specificity due to this crop and especially a real dependency to the favorable climatic condition of that agricultural year (Tab. 1, 2).

Based on technical analysis, consistent with the average production results obtained in 2011 - 2012 - 2013, with all the high variability of the grain production, it is possible to obtain maximum yields of $8128 \mathrm{~kg} / \mathrm{ha}$ at a complex dose of N183P93. Large differences in production from year to year and the production increases per active substance unit prove the influence of the years (with climatic effects) on the effectiveness of applying fertilizers to corn. From this point of view, only the results in 2011 can be conclusive for a correct technical and economical analysis.

For corn crops were taken into consideration the efficiency parameters and indicators for 2011 when the productions were constantly of 12-14 $\mathrm{t}$ grains/ha and annual production increases of 3-7,5 $\mathrm{t}$ grains/ha. For corn, the quantification of

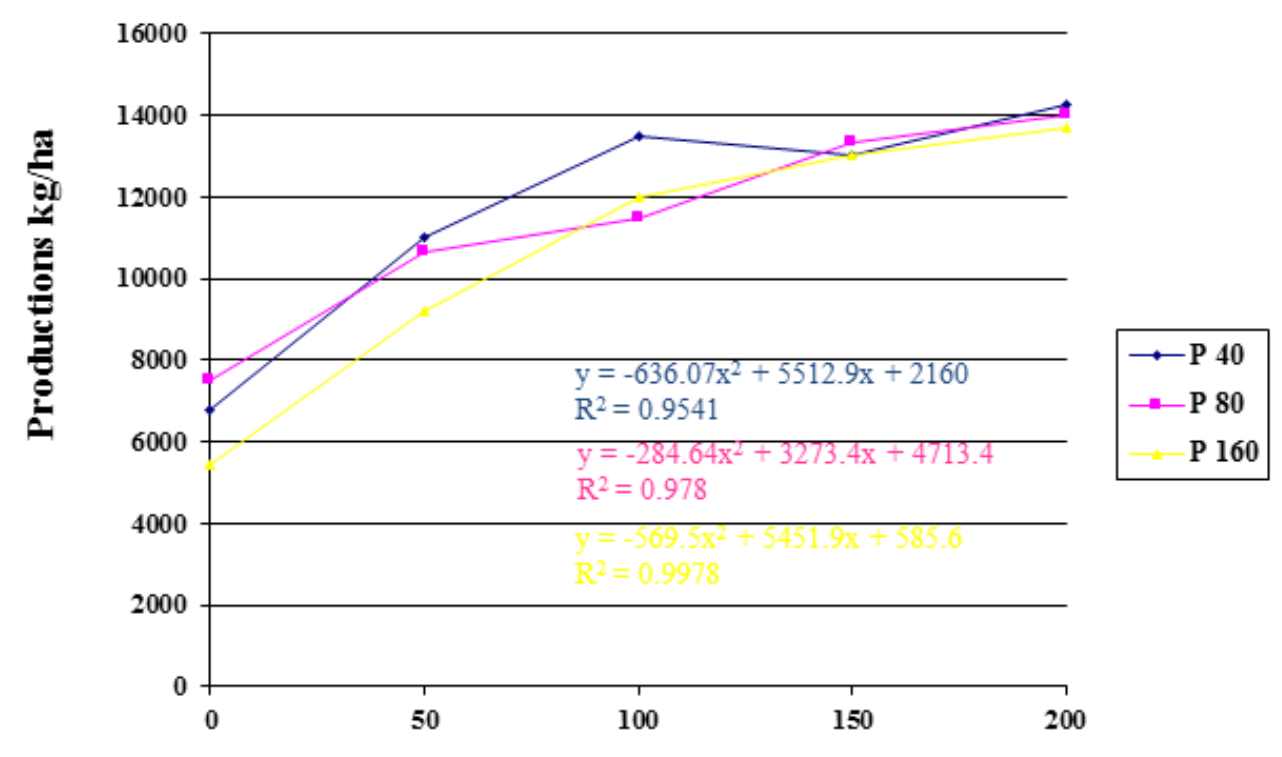

N Doses

Fig. 1. Effect of differentiated fertilization (NP) on the production of grain $(\mathrm{kg} / \mathrm{ha})$ obtained from corn grown after wheat in 2011 
Tab. 1. Summary indicators of fertilizer applied to corn crop (Variety Turda STAR)

\begin{tabular}{lccc}
\hline Years & Maximum production (kg/ha) & NP Dose & Significance of factors influence ${ }^{\mathrm{x}}$ \\
\hline 2011 & 13696 & N200P160 & NP - f. d. s.; N - f. d. s.; P - n. s. \\
\hline 2012 & 4194 & N150P40 & NP - n. s.; N - n. s.; P - n. s. \\
\hline 2013 & 6493 & N200P80 & NP - d. s.; N - d. s.; P - n. s. \\
\hline Mean & 8128 & N183P93 & \\
\hline${ }^{\mathrm{x}}$ f. d. s. - very distinctly significant; d. s. - distinctly significant; s. - significant; n. s. - insignificant
\end{tabular}

${ }^{\mathrm{x}}$ f. d. s. - very distinctly significant; d. s. - distinctly significant; s. - significant; n. s. - insignificant

Tab. 2. Report on production and maximum increases to the content of a. $\mathrm{s}$./hectare $(\mathrm{N}+\mathrm{P})$

\begin{tabular}{ccccccc}
\hline Year & Crop & $\begin{array}{c}\text { Maximum production } \\
(\mathrm{kg} / \mathrm{ha})\end{array}$ & NP Dose & Dose sum N+P & Production/NP dose $\begin{array}{c}\text { Prod. Dif./NP } \\
\text { dose }\end{array}$ \\
\hline 2011 & Corn & 13696 & N200P160 & 360 & 38 & 19 \\
\hline 2012 & Corn & 4194 & N150P40 & 190 & 22 & 2 \\
\hline 2013 & Corn & 6493 & N200P80 & 280 & 23 & 2,5 \\
\hline Mean & Corn & 8128 & N183P93 & 276 & 23 & 5,3 \\
\hline
\end{tabular}

${ }^{\mathrm{x}]}$ a. s. - active substance

the economic efficiency indicators was developed with reference to the framework technology parameters for this crop (according to data from SCDA Turda) (Tab. 3).

The rate of return, as a mean that derives from all NP combinations, exhibits a very high level, with a maximum of the individual values at N200P160 fertilizing combination, at which the production increase value due to the applied dose was maximum $(6041 \mathrm{~kg} / \mathrm{ha})$ and the revenue obtained for 1 leu was double, which shows that in case of corn, for Turda STAR variety, applying an intense fertilization, it can be obtained 12-14 $\mathrm{t}$ of grains per hectare. Production and economic results obtained in 2011 are reference results regarding the ones obtained in 2012 (totally unfavorable from the climatic point of view) and 2013, mentioning that due to the excessive heat, more acute in 2012, the results obtained in these years were insignificant regarding the fertilization effects.

The illustration of the way of manifestation of the dependencies of average productions per hectare on the two fertilizing factors applied $\left(\mathrm{x}_{1}\right.$ $=$ dose of $\mathrm{P}$ a. $\mathrm{s}$. $/$ ha and $\mathrm{x}_{2}=$ dose of $\mathrm{N}$ a. s./ha) (Tab. 4) can be graphically expressed through response surfaces. This illustration exhibits the evolution of average productions in relation to $\mathrm{P}$ doses ( $\mathrm{x} 1$ ) and $\mathrm{N}$ doses ( $\mathrm{x} 2$ ), it highlights the areas of the positive $\mathrm{x}_{1} \mathrm{x}_{2}$ interactions and suggests the production levels, for corn, probable on the argic chernozem and that may extrapolate the obtained results (Fig. 2, 3).

The research on the situation of economic optimum doses shows that on an argic chernozem type of soil, the essential and recommended element is nitrogen. Corn crops responded to the application and even over-dosage of nitrogen - which can sustain high and economical productions per surface unit.

The current research takes the approach of such suitable fertilizing systems for this particular genotype and on this specific type of soil to a level regarding its economic efficiency, through this delivering information and practical solutions for those interested in cultivating this corn genotype.

The degree of novelty of this research can be expressed through the fact that for the type of soil and genotypes used in these experiments could be established fertilization solutions and synthesized mathematical models holding a high dissemination and applicability value in similar ecologic conditions.

\section{CONCLUSION}

Statistically it was proven to be essential and very distinctly significant the effect of NP interaction for corn crops, followed by the individual action of nitrogen and less of the phosphorus;

For corn crops, the variation and variability of the effect of the attracted factors $\left(\mathrm{x}_{1}-\mathrm{P}\right.$ and $\mathrm{x}_{2}-$ 
Tab. 3. Economic efficiency indicators for corn grown in 2011 (Vs; Cs; Vs/1 leu Cs) (lei)

\begin{tabular}{|c|c|c|c|c|c|c|c|c|}
\hline $\mathrm{N}$ & Economic efficiency indicators & $\mathrm{P} \rightarrow$ & 0 & 40 & 80 & 120 & 160 & Mean \\
\hline \multirow{3}{*}{0} & Vs & \multirow{3}{*}{-} & \multirow{3}{*}{-} & \multirow{3}{*}{ - } & \multirow{3}{*}{-} & \multirow{3}{*}{-} & \multirow{3}{*}{-} & \multirow{3}{*}{-} \\
\hline & Cs & & & & & & & \\
\hline & Vs/1 leu & & & & & & & \\
\hline \multirow{3}{*}{50} & Vs & & 3653 & 4014 & 3004 & 3695 & 3571 & 3587 \\
\hline & Cs & & 3068 & 3068 & 3068 & 3068 & 3068 & 3068 \\
\hline & Vs/1 leu & & 1.19 & 1.3 & 0.97 & 1.2 & 1.16 & 1.16 \\
\hline \multirow{3}{*}{100} & Vs & & 5289 & 6357 & 3786 & 6407 & 6232 & 5614 \\
\hline & Cs & & 3068 & 3068 & 3068 & 3068 & 3068 & 3068 \\
\hline & Vs/1 leu & & 1.72 & 2.07 & 1.23 & 2.08 & 2.03 & 1.83 \\
\hline \multirow{3}{*}{150} & Vs & & 4813 & 5929 & 5540 & 6049 & 7220 & 5910 \\
\hline & Cs & & 3068 & 3068 & 3068 & 3068 & 3068 & 3068 \\
\hline & Vs/1 leu & & 1.57 & 1.71 & 1.8 & 1.97 & 2.35 & 1.88 \\
\hline \multirow{3}{*}{200} & Vs & & 6275 & 7099 & 6167 & 7579 & 7141 & 6853 \\
\hline & Cs & & 3068 & 3068 & 3068 & 3068 & 3068 & 3068 \\
\hline & Vs/1 leu & & 2.04 & 2.31 & 2.01 & 2.47 & 2.55 & 2.28 \\
\hline \multirow{3}{*}{ Mean } & Vs & & 5008 & 5850 & 4624 & 5933 & 6041 & 5491 \\
\hline & Cs & & 3068 & 3068 & 3068 & 3068 & 3068 & 3068 \\
\hline & Vs/1 leu & & 1.63 & 1.85 & 1.5 & 1.93 & 2.02 & 1.43 \\
\hline \multicolumn{9}{|c|}{ Rate of return (Vn; Rr) (lei; \%) } \\
\hline $\mathrm{N}$ & Economic efficiency indicators & $\mathrm{P} \rightarrow$ & 0 & 40 & 80 & 120 & 160 & Mean \\
\hline \multirow{2}{*}{0} & $\mathrm{Vn}$ & \multirow{2}{*}{\multicolumn{2}{|c|}{ - }} & \multirow{2}{*}{ - } & \multirow{2}{*}{-} & \multirow{2}{*}{-} & \multirow{2}{*}{-} & \multirow{2}{*}{-} \\
\hline & $\mathrm{Rr}$ & & & & & & & \\
\hline \multirow{2}{*}{50} & $\mathrm{Vn}$ & & 585 & 946 & -64 & 627 & 503 & 519 \\
\hline & $\mathrm{Rr}$ & & 19 & 30 & -2 & 20 & 16 & 17 \\
\hline \multirow{2}{*}{100} & $\mathrm{Vn}$ & & 2221 & 3289 & 718 & 3339 & 3164 & 3546 \\
\hline & $\mathrm{Rr}$ & & 72 & 107 & 23 & 108 & 103 & 83 \\
\hline \multirow{2}{*}{150} & $\mathrm{Vn}$ & & 1568 & 2861 & 2472 & 2981 & 4152 & 2807 \\
\hline & $\mathrm{Rr}$ & & 51 & 93 & 80 & 97 & 135 & 91 \\
\hline \multirow{2}{*}{200} & $\mathrm{Vn}$ & & 3207 & 4031 & 3099 & 4511 & 4773 & 3924 \\
\hline & $\mathrm{Rr}$ & & 105 & 131 & 101 & 147 & 155 & 128 \\
\hline \multirow{2}{*}{ Mean } & $\mathrm{Vn}$ & & 1895 & 2782 & 1556 & 2865 & 3148 & 2449 \\
\hline & $\mathrm{Rr}$ & & 62 & 90 & 40 & 93 & 102 & 80 \\
\hline
\end{tabular}

Tab. 4. Bi-factorial functions of the wheat and corn yield dependency on $\mathrm{P}$ and $\mathrm{N}$ doses (according to data from 2011-2013)

\begin{tabular}{ccc}
\hline Crop & Year & The function of grain production (y) according to factors $\mathrm{x}_{1}\left(\mathrm{P}\right.$ dose) and $\mathrm{x}_{2}$ (N dose) \\
\hline \multirow{2}{*}{ Corn } & 2011 & $\mathrm{y}=6530,01+17,25 \mathrm{x}_{1}-0,12 \mathrm{x}_{1}{ }^{2}+74,89 \mathrm{x}_{2}-0,2 \mathrm{x}_{2}{ }^{2}$ \\
\cline { 2 - 3 } & 2013 & $\mathrm{y}=5365,13+5,07 \mathrm{x}_{1}-0,04 \mathrm{x}_{1}{ }^{2}+4,83 \mathrm{x}_{2}-0,01 \mathrm{x}_{2}{ }^{2}$ \\
\hline
\end{tabular}

N) were higher, production results being much different between 2011, 2012, 2013. The most favorable year in terms of climate was 2011, and in 2012 and 2013 excess heat (during the decisive phenol-phases of corn) caused lower results. 


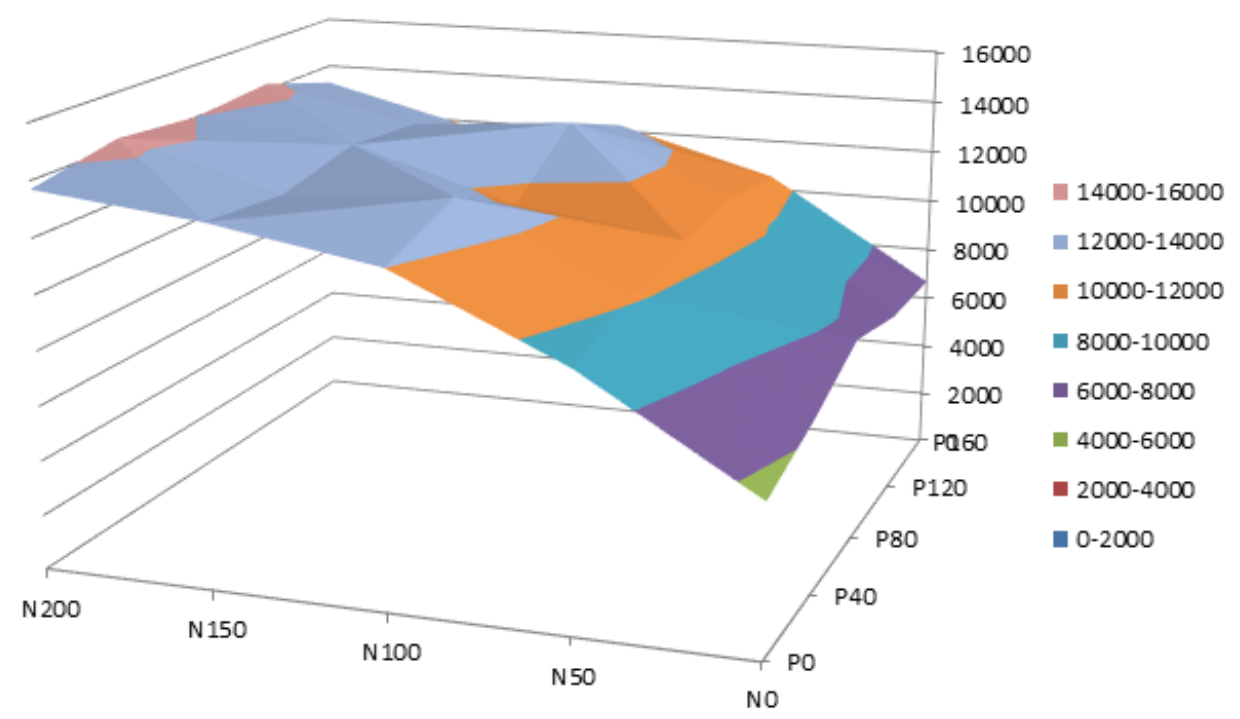

Fig. 2. Differentiated fertilization (NP) effect on the production of corn (2011)

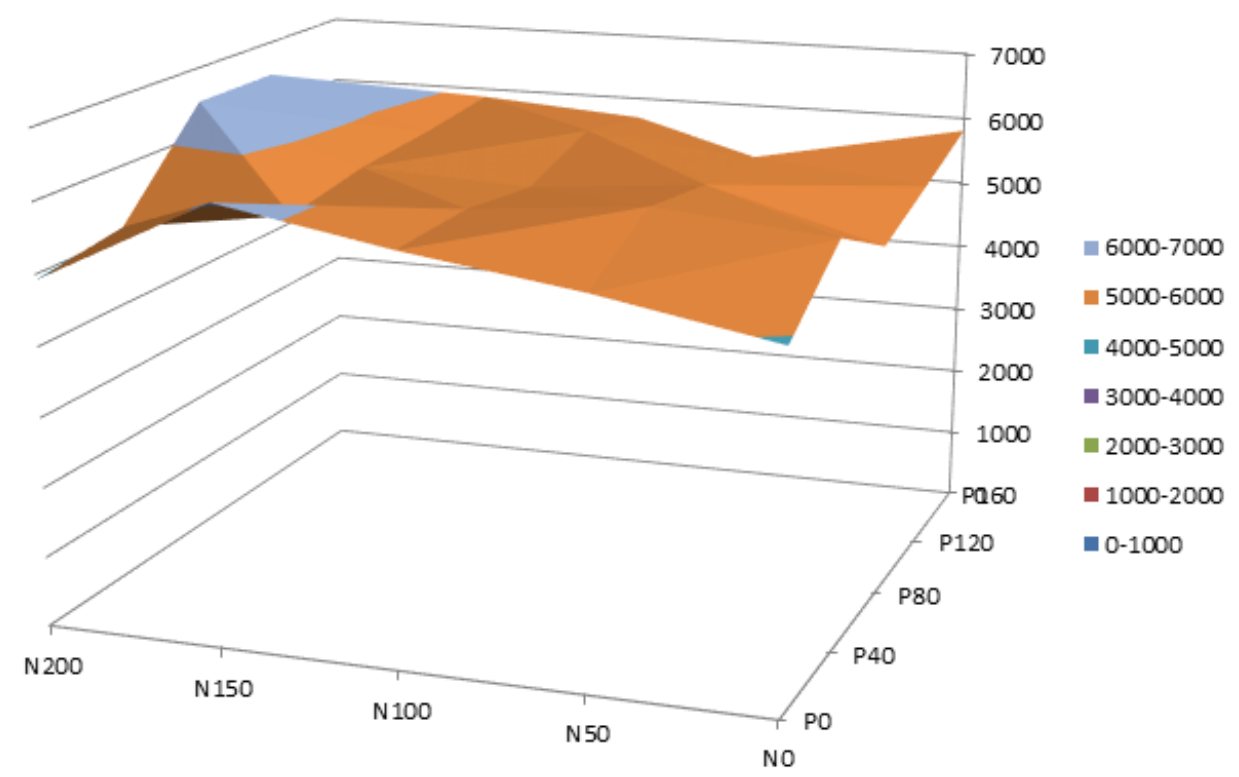

Fig. 3. Differentiated fertilization (NP) effect on the production of corn (2013)

In 2011, Turda STAR hybrid responded with grain yields of 12-14 t/ha, with increases in NP interaction accounted for only $1 / 2$ and over half of the grain production. This hybrid harnessed the NP interaction, at average and high doses of both nutrients. Technical results of 2012, for corn, due to thermal disorder, have shown no effect to the combinations of the fertilizers applied. In 2013 were reported some effects of fertilizers, but exhibited erratically and without statistical support.
Economic analysis of the results of differentiated fertilization highlights high economic variability of the combinations of $\mathrm{x}_{1}(\mathrm{P}$ doses) and $\mathrm{x}_{2}$ (doses of $\mathrm{N}$ ). This variability occurs from the level of production, the level and value of production increases obtained, equally important and essential, from the amount of additional costs due to fertilization. From here, it results the net income that is differentiated from the values of the mentioned indicators and differentiated from the values obtained per 1 leu extra costs with fertilization; 
The rates of return of fertilization on corn in 2011, show a high efficiency of complex measures of NP and even of the primarily application of nitrogen. With high levels of production of 12-14 $\mathrm{t}$ grains/ha and increases of 4-6 t/ha due to the application of some NP combinations, the rates of return are very high and positive feedback justifies such activities;

Optimization of fertilization was made methodologically with the production and profit functions (derived from costs and income). For corn, in 2011, the values of the economic optimum doses are: $\mathrm{DOE}_{\mathrm{N}}-183,6 \mathrm{~kg} / \mathrm{ha}, \mathrm{DOE}_{\mathrm{p}}-65,62 \mathrm{~kg} /$ ha, and in 2013, DOE $_{\mathrm{N}}-169 \mathrm{~kg} / \mathrm{ha}, \mathrm{DOE}_{\mathrm{P}}-44,62$ $\mathrm{kg} / \mathrm{ha}$.

Economic optimum doses and technical optimum doses insure and forecast the production levels that stood at the base of developing the bifactorial functions of the productions that have derived from the results and technical analysis of corn productions.

The aspects that can limit such a study regarding the economic optimization of fertilizing systems may refer to impact limitations, as the research is conducted on a particular type of soil specific to the north-west region of Romania. To overcome this limitation, the same study could be conducted in other regions of the county, using the same genotype in order to achieve data for a comparison analysis.

\section{REFERENCES}

1. Borlan Z, HERA C (1984). Agrochemical optimization of soil-plant system, Romanian Academy Publishing House, București.

2. Borlan Z, Hera C, Dornescu D, Kurtinecz P, Rusu M, Buzdugan I, Tănase G (1994). Fertility and fertilization of soils (Agrochemistry compendium). Ceres, București.

3. Haș I (2006). Production of seeds for agricultural plants. Academic Press, Cluj-Napoca.

4. Hera C (2008). Fertilizers and sustainable agriculture, ProcEditura of the Int. Symp. CIEC, Pretoria- South Africa.

5. Otiman $P$ (1979). Regarding automatic generation of optimization models for agricultural activities. Agronomie Scientific Papers, nr. 16, Timişoara.

6. Otiman P (1987). Optimization of agricultural production. Facla, Timișoara.

7. Otiman P, Creţ F (2002). Mathematic elements applied in agriculture and food economy. Agroprint, Timişoara.

8. Poruţiu A, Rusu M, Mărghitaş M, Toader C, Moldovan L, Deac V, Chețan F (2013). Research Concerning the Agrochemical Optimization of the Fertilization System for Wheat Crops on an Argic Phaeozem Soil in the Transylvanian Plain. Research Journal of Agricultural Science, 45 (1), Timişoara.

9. Toader C, Mărghitaş M, Poruţiu A, Moldovan L, Mihai M (2013). The Organo-Mineral Fertilization Influence at Corn Crops on the Soil Agrochemical Indicators and the Accumulation of Nutrients in the Maize and in the Corn Leaves for Identifying Some Nutritional Disorders (Potassium Deficiency). Research Journal of Agricultural Science, 45 (3), Timişoara. 